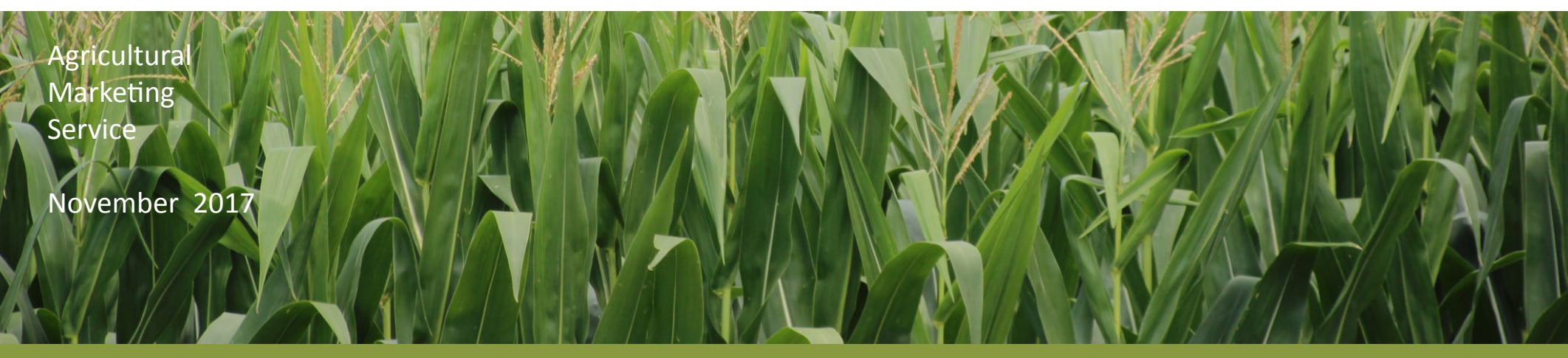

\title{
Analysis of Grain Basis Behavior during Transportation Disruptions (Summary)
}

Peter Caffarelli and Adam Sparger

This is a summary of Staff Report \#17-SR 111, "Analysis of Grain Basis Behavior during Transportation Disruptions and Development of Weekly Grain Basis Indicators for the USDA Grain Transportation Report" by Chad Hart (Department of Economics, lowa State University) and Frayne Olson (Department of Agribusiness and Applied Economics, North Dakota State University). This paper received funding from USDA's Agricultural Marketing Service (AMS) through cooperative agreement number 14-TMXXX-IA-0028. The opinions and conclusions expressed are the authors and do not necessarily represent the views of USDA or AMS. The full report is available at http://www.card.iastate.edu/products/publications/pdf/17sr111.pdf.

\section{WHAT IS THE ISSUE?}

Basis is an important market mechanism generally reflecting the cost of marketing grain at one location as compared to another. It affects when and where many grain producers and shippers buy and sell grain. Many factors contribute to these market signals, but transportation is usually the largest cost component associated with basis, either directly through shipping costs, or indirectly, for example, through transport availability. Thus, disruptions to the transportation system can have serious impacts on basis.

Basis is the difference between the local cash (spot) price and the futures price for a commodity. The mathematical expression of basis is: Basis = Cash Price - Futures Price.

Local cash prices reflect local supply and demand forces, while futures markets reflect global supply and demand forces. Taken together, basis is an important signaling mechanism in grain markets. When local supplies are tight relative to demand, cash prices will rise, resulting in a more positive (or less negative) basis. This causes the basis to narrow or strengthen. Crop merchandizers strengthen basis to increase the flow of grain. Conversely, basis widens or weakens when it becomes less positive (or more negative). Merchandizers weaken basis to slow the flow of grain. As the cash price falls relative to the futures price, the incentive to store grain increases.

In addition to transportation, many other factors affect basis, such as local storage capacity and crop quality. Interactions among these variables, especially as they relate to transportation, is complex, multifaceted, and not fully understood by many. This research explores grain basis behavior during transportation disruptions and provides recommendations for basis data collection in the Grain Transportation Report (GTR). 
The study consisted of three main parts: (1) exploratory analysis examining basis patterns over time and across space; (2) development of a regression model to understand relationships of several independent variables on basis in the Corn Belt; and (3) development of a similar regression model to understand factors affecting the basis for major wheat market locations.

For the first part of the research, the authors chose four representative markets of major production and shipping areas for corn, soybeans, and wheat to examine pricing and basis patterns: (1) Fargo, ND; (2) Williston, ND; (3) Davenport, IA; and (4) Cairo, IL. These areas allow an examination of the impact of increased energy (ethanol and oil) production on grain transportation costs; explore areas of expected growth for trade routes along the U.S.-Canadian border; and reveal geographic differences in basis as products move through different shipping channels. Grain price data from these areas came from GeoGrain and AMS Market News. Data on county crop production, livestock production, biofuel production, and exports came from USDA's National Agricultural Statistics Service and university sources. Transportation data-such as rail tariff rates, secondary rail market rates, ocean freight rates, and diesel fuel prices-came from AMS' GTR datasets.

For the second and third parts of the research, regression models were developed to examine the factors affecting grain basis for multiple locations, spanning the major corn, soybean, and wheat production areas (e.g., northern lowa, southern lowa, southern Minnesota, etc.) and were estimated using ordinary least squares with the following equation.

$$
\begin{aligned}
\text { Basis } & =b_{0}+b_{1}(\text { March })+b_{2}(\text { May })+b_{3}(\text { July })+b_{4}(\text { September })+b_{5}(\text { Ethanol })+b_{6}(\text { Livestock }) \\
& +b_{7}(\text { Hurricane })+b_{8}(\text { S\&P })+b_{9}(\text { Diesel })+b_{10}(\text { Gulf Basis })+b_{11}(\text { Shuttle })+b_{12}(\text { Winter }) \\
& +b_{13}(\text { Drought })+e
\end{aligned}
$$

The first few variables ("March," "May," "July," and "September") take into account futures contract shifts, as basis can jump when different futures contracts are used. ${ }^{1}$ The "Ethanol" and "Livestock" variables capture local demand factors, while "S\&P" serves as a proxy of general economic conditions. The variables of "Hurricane" and "Winter" are included as indicator variables that take into account factors affecting the transportation system, specifically the 2-week period following a hurricane in the Gulf of Mexico and the periods of closure for the Upper Mississippi River due to ice. Similarly, "Drought" is an indicator variable that notes the impact of the 2012 drought. Other transportation-related variables - "Diesel," "Gulf Basis," and "Shuttle" - measure the price of diesel fuel, the ocean freight rate from the Gulf of Mexico to Japan, and rates in the secondary rail auction market, respectively.

\section{What did THE STUdy Find?}

\section{Results from Exploratory Analyses}

Hart and Olson showed that basis fluctuates throughout the marketing year, typically strengthening (or improving) in the months after harvest. This is because local harvests boost supplies, which depress basis, all else constant. As the marketing year progresses, the filling of demand needs (from livestock, ethanol, exports, and other uses) decreases supplies, leading to improvements in basis. Figure 1 plots the corn basis in three Illinois locations, which is a crop Illinois farmers primarily harvest in late September and October. Generally, there is an upward trend in basis from the beginning to the end of the marketing year.

1 As the researchers note, this tends to happen at the beginning of the contract month. For example, corn may experience jumps at the contract months, September 1, December 1, March 1, May 1, and July 1. 
Basis also varies with location. For example, given their proximity to the export terminals in the Gulf, basis levels in southern and eastern lowa tend to be higher than those for southern Minnesota and northern and western lowa (Figure 2). The authors explain that areas closer to demand centers typically have a stronger basis. In many of these locations, the expansion of ethanol over the past decade has boosted local demand for grain and increased local cash prices, which have generally led to higher basis levels.

In addition, Hart and Olson provided a visual depiction of how transportation disruptions, such as a hurricane halting exports in the Gulf, can affect basis. As a comparison, Figure 3 shows a typical pattern for corn basis, where Figure 4 shows the corn basis shortly after Hurricane Katrina. In both images, the orange and red coloring indicates a stronger (or narrower) basis, and the green and blue coloring indicates a weaker (or wider) basis. As the authors explain, "basis tends to be weak [green/blue] in areas where local supply is large relative to demand and strong [orange/red] where demand is large relative to local supply. One can think of basis as the price signal to move the crop towards the areas where crop demands are relatively stronger." As a result, basis is normally stronger along the river and near the Gulf of Mexico (Figure 3). However, Hurricane Katrina significantly disrupted flows out of the Gulf, and consequently halted barge traffic. Grain shippers faced increased costs implementing alternative transportation options and delaying shipments. Basis levels weakened to offset those financial impacts and slow down the flow of crop.

\section{Results from Regression Analyses}

Most of the regression results aligned with expectations. For instance, the researchers generally observed improvement in basis over the marketing year. In lowa, demand factors (such as ethanol and livestock) had mostly positive and significant relationships with basis, meaning that increases in local demand correspond to a stronger basis. However, this was not the case for locations in Illinois, where the "Ethanol" and "Livestock" generally had a negative relationship with basis and were not all significant. The wheat model found that as demand increases (reflected in export levels) basis tends to strengthen.
Figure 1: Average corn basis for USDA-AMS reported prices for Illinois.

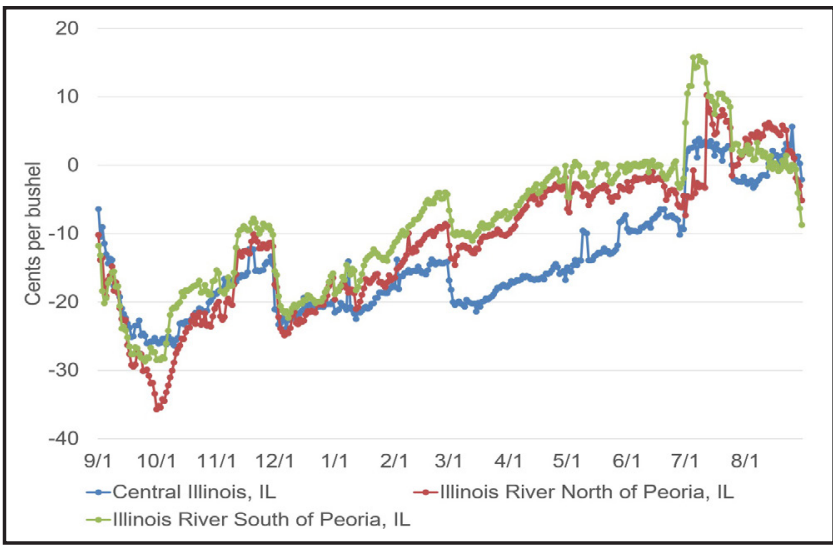

Source: Hart and Olson, 2017 (Figure 7).

Figure 2: Average corn basis for USDA-AMS reported prices for lowa and southern Minnesota.

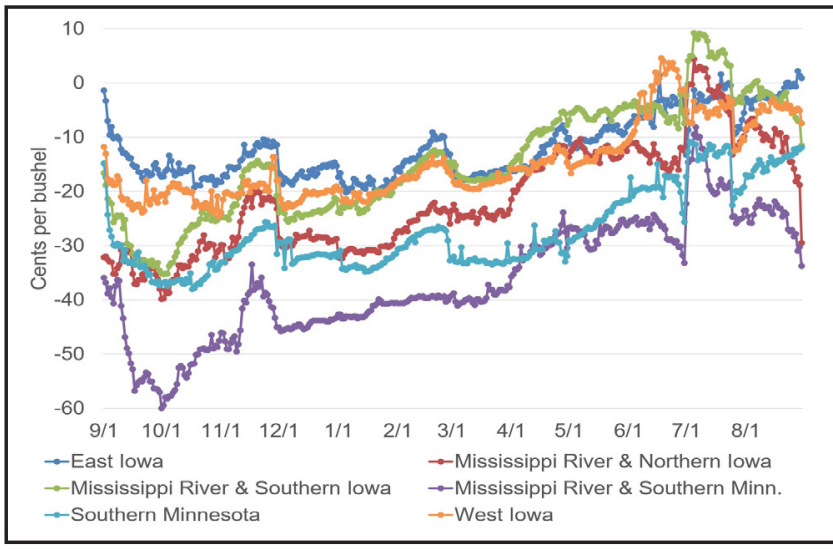

Source: Hart and Olson, 2017 (Figure 6).

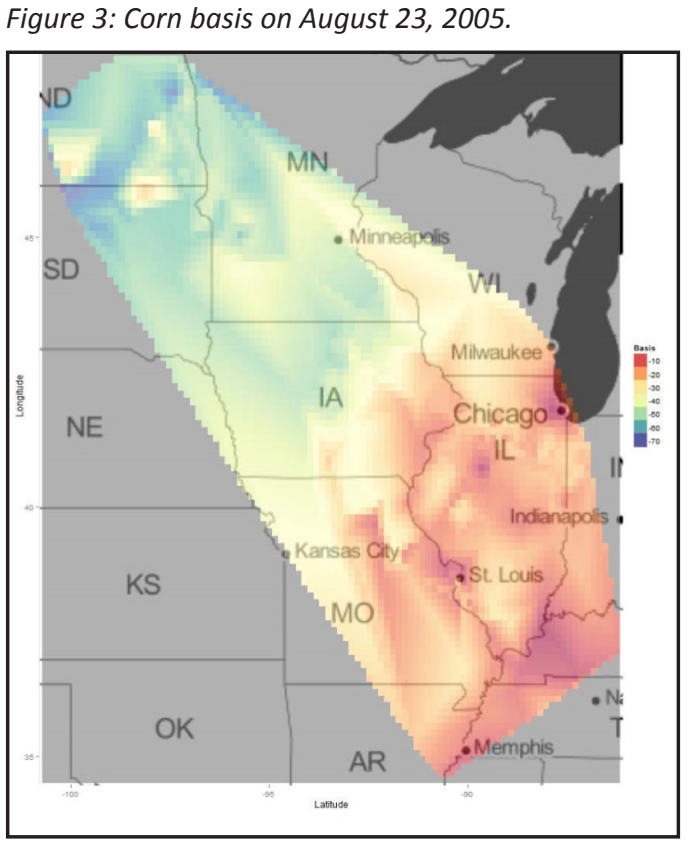

Source: Hart and Olson, 2017 (Figure 1). 
In terms of transportation disruptions, the hurricane impact ("Hurricane") was not significant across lowa, but the winter closure impact ("Winter") was for four out of the six lowa locations. Comparatively, "Hurricane" and "Winter" were significant factors on basis for the Illinois locations, with "Hurricane" almost twice the size. The authors write, "This makes sense as Illinois is closer to the Gulf and further away from the winter river stoppages. The hurricane impact is also larger at the barge loading elevators along the Illinois River than it is for the country elevators. Again, this makes sense based on the barge loading elevators' greater reliance on river transportation to reach crop users."

Transportation costs-reflected in diesel rates ("Diesel"), ocean freight rates ("Gulf"), rail tariff rates (included in the wheat model), and rates in the secondary rail auction market ("Shuttle")-were almost all significant across the locations in lowa, Illinois, North Dakota, and Montana. The coefficients on the variables were negative, aligning with expectations that increases in transportation costs translate into weaker basis levels. In other words, "the results show that increases in the tariff rates, fuel surcharges, and the costs of transportation in the secondary markets have a direct, inverse impact on basis." In one example, Hart and Olson found that a $\$ 1$ change in the price of diesel was associated with a $\$ 0.17$ decrease in basis in east lowa. The authors concluded that: "transportation costs are a major component in basis setting." Further, they emphasize, "there are a number of factors that influence basis at any given time, and the influence of these factors on basis levels depends on the specific combination of crop, location, and time period."

\section{CONCLUSIONS}

The study found that increased local production and higher transportation costs are associated with wider basis levels. In contrast, higher local usage, via ethanol or livestock, is associated with narrower basis levels. In addition, there are some distinct seasonal patterns to basis, which vary by region. They found mixed impacts from natural disasters, again depending on the region of the country. The variables chosen to model basis held the most explanatory power for regions closer to the major shipping channel, the Mississippi River system. This suggests that other variables are needed to explain changes in basis for regions further away from the Mississippi River in addition to those used for this study.

\section{Study ReCOMMENDATIONS}

The study offered three recommendations to AMS. Briefly:

1. Consider providing basis data in the GTR, such as a basis summary map.

2. Continue to provide information on prices in the secondary rail transportation markets in the GTR because transportation costs are a major factor for grain basis.

3. Expand (currently limited) coverage of grain prices in the Upper Plains region to the extent possible. 


\section{Preferred Citation}

Caffarelli, Peter and Adam Sparger, Analysis of Grain Basis Behavior during Transportation Disruptions (Summary), U.S. Department of Agriculture, Agricultural Marketing Service, November 2017. Web. http://dx.doi.org/10.9752/TS215.11-2017.

USDA is an equal opportunity provider, employer, and lender.

Photo credit: USDA 